For the bacon pigs subjected to restricted feeding with diets containing $3300 \mathrm{kcal}$ D.E. supplying 2.50 to $2.60 \mathrm{~g}$ lysine for $1000 \mathrm{kcal}$ D.E. and offered in the trough as a moistened meal, the presence of 5 points lupin did not alter the performance as compared to the control diet only composed of maize and soybean meal. At the level of 10 points, a decrease in growth rate as well as a 4 p. 100 increase in the feed conversion ratio were observed over the whole fattening period. These discrepancies only occurred during the finishing period. At the level of 15 points the performance were highly reduced (by 10 p. 100) and the animals exhibited flatulence troubles accompanied by a reduced appetite. Use of flax seeds as curative or preventive treatment undoubtedly reduced the magnitude of these phenomena, which are probably due to the bad digestion of alphagalactosides whose proportion is rather high in this type of lupin (8 p. 100 stachyose).

A reduction in the carcass yield was noticed in pigs fed lupin containing diets but it has to be pointed out that 10 and 15 points lupin led to an improvement of the body composition.

\title{
Nutritional value of whole extruded soyabean seeds in piglet feeding
}

\author{
A. AUMAITRE, D. BOURDON \\ INV.R.A., Station de Recherches sur l'Elevage des Porcs, \\ Centre de Rennes-Saint-Gilles, F 35590 L'Hermitage
}

Soybean oil-meal intended for monogastric animals has to be subjected to heat treatments so as to improve its nutritional value. Possible use of whole soybean seeds gives rise to a double problem involving the presence of antinutritional factors and a high lipid level. Moreover, only little accurate information is available on the possible use of such a feed in early weaning diets for piglets.

This experiment allowed to compare a classical diet composed of maize-soybean meal (70 and 22 p. 100) with a almost isoenergic diet composed of barley, a moderately energy rich cereal associated with whole extruded soybean seed $(67$ and 25 p. 100). Piglet performance measured between 5 and 10 weeks of age showed that whole extruded seed which contained less than 0.8 ITU of antitrypsine factor per $\mathrm{mg}$ was as valuable a protein source as soybean meal. Both diets were equally consumed (866 versus $876 \mathrm{~g} /$ day) and the daily mean gain was similar for both treatments (444 versus $447 \mathrm{~g}$ /day). Feed conversion ratios were identical (1.95 versus $1.94 \mathrm{~kg}$ of diet per $\mathrm{kg}$ weight gain). A supplementary isoenergetic diet based on barley-soybean-meal and tallow led to equivalent mean performance.

However, the adaptation of the animals varied according to diet composition. Performances during the different periods between 8.4 and $24 \mathrm{~kg}$ were discussed. Conclusions were drawn as regards the efficiency of the extrusion in suppressing antinutritional factors and the economic conditions of the use of whole soybean seeds in weaning diets for piglets.

\section{Choice of the protein sequence during post-weaning (ad libitum) and fattening periods (restricted)}

\author{
F. GROSJEAN *, J. CASTAING **, O. LAVOREL *, M. LEUILLET * \\ * I.T.C.F., 8, avenue du Président-Wilson, F 75116 Paris \\ ** A.G.P.M., 122, boulevard Tourasse, F 64000 Pau
} $103 \mathrm{~kg}$.

Two experiments were carried out with 256 Large White pigs weighing from 9 to

In the first experiment we studied the subsequent effect of the post-weaning protein level $(21$ or 18 p. 100 crude protein) on bacon pigs receiving a suitable level of protein (18 p. 100). The following sequences were compared : 21-18 and 18-18. 
In the second experiment, 4 protein sequences were compared in order to determine whether the protein level during fattening was related to the post-weaning level (interaction?). The four sequences were chosen so as to represent the 4 currently encountered possibilities (high-high, i.e. 22-18 p. 100 crude protein, high-low, 22-15 p. 100, low-high, 18-18 p. 100, low-low, $18-15$ p. 100).

Post-weaning protein level had no significant subsequent effect during fattening, either on growth or body composition.

No statistically significant interaction between post-weaning and fattening protein levels was evidenced with the 4 sequencies of the second experiment.

Thus, the protein sequence to be chosen should be that supplying optimum growth performance during each period, i.e. 22-18 p. 100. However the farmer (rearer/feeder) manufacturing the feeds himself might prefer to make one only feed. He should then choose sequence 18-18 giving similar results as sequence 22-18.

\title{
Influence of management system (separation or mixing of sexes) on the performance of castrated male pigs and females
}

\author{
F. GROSJEAN *, B. CHAMBON **, J. CASTAING ***, J. CHAUVEL ****, \\ P. LATIMIER *****, D. LE MEUR $* * * * * *$, P. QUEMERE $* * * * * * *$ \\ *I.T.C.F., ** Stagiaire à l'I.T.C.F., *** A.G.P.M., **** I.T.P., \\ ***** E.D.E. 22, ***** E.D.E. 29, ******** S.E.R.E.P. \\ (France)
}

Five experiments involving 208 castrated males and 108 females were carried out in order to determine whether the mixing of sexes affects the performance of the animals.

All animals were fed according to the same feeding schedule based upon live weight. Maximum level of restriction was $7945 \mathrm{kcal}$ D.E./day from $60 \mathrm{~kg}$ during 2 experiments and $9000 \mathrm{kcal}$ D.E./ day from $70 \mathrm{~kg}$, during 3 experiments.

Each experiment involved 3-5 replications and each replication involved 4 types of pens; 1 with castrated males, 1 with females and 2 with an equal number of males and females together.

During the first analysis, we compared (for each criterion) the average growth and slaughter performance of males and females kept separately, and those of the group of males and females mixed together. During the second analysis, we measured the effect of mixing upon each sex.

The results of these 5 trials show that the management system did not significantly affect either the growth criterion (growth rate, food conversion ratio) or the carcass traits (dressing percentage, side backfat thickness and grading).

Mixing the animals seemed to favour the growth of castrated males more than that of the females, but this was probably due to the domination of the males at the trough. However, this effect was not very clear as regards the carcass composition of these animals.

\section{A comparative study concerning the utilization of pellets of different diameters by the weaned piglet}

\author{
O. LAVOREL, J. FEKETE, M. LEUILLET \\ I.T.C.F., 8, avenue du Président-Wilson, F 75116 Paris
}

Four different physical forms of post-weaning feeds (1st and 2nd age) were compared : dry flour, pellets of $2.5,3$ and $5 \mathrm{~mm}$ diameter. 